Hunger, by V. H. Mottram, Fellow of Trinity College, Cambridge, Plates 2 and 3 , from the physiological laboratories of Cambridge and Munich. 7. The Mode of Action of Specific Substances, with Special Reference to Secretin, by W. E. Dixon and P. H. A. Mill, from the pharmacological laboratory, Cambridge. 8. The Pressor Principles of Placental Extracts, by Otto Rosenheim, from the physiological laboratory, King's College, London. 9. Isolation of the Pressor Principles of Putrid Meat, by G. Barger and G. S. Walpole, from the Wellcome physiological laboratories, London. This number contains also the Proceedings of the Physiological Society for Feb. 27th, 1909.

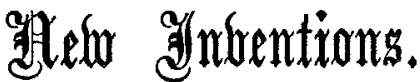

\section{AN IMPROVED INHALATION AND DISINFECTION APPARATUS.}

THIs invention is designed to afford an improved apparatus for impregnating air with drugs and for inhalation purposes. The ordinary spray apparatus, such as the nebuliser, do not effectively answer their purpose, because the substances used in them, however minutely divided, are yet, taken in the aggregate, necessarily delivered in the form of drops of liquid so used. Again, the drug used does not reach the whole of the lung substance, a great deal of it settling in the bronchi and upper portions of the lung. This apparatus, which is shown in section in the figure, consists of a boiler, $A$, having a

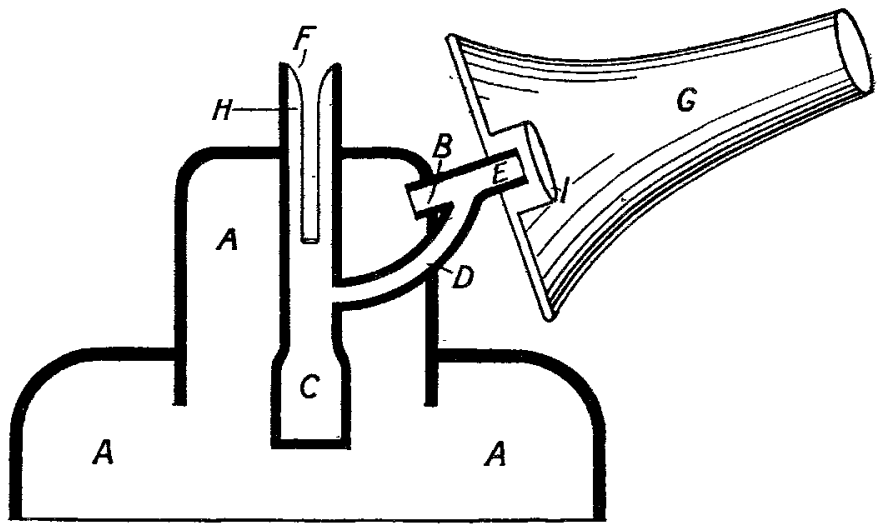

nozzle outlet, $\mathrm{B}$, and a receptacle, $\mathrm{C}$, in which the substance is volatilised and which is contained within the boiler but does not directly communicate with it. This receptacle has an air inlet and a nozzle outlet, D, located in apposition with the boiler outlet in such a manner that the steam issuing from the latter sucks up the vapour of the substance under volatilisation contained in the receptacle and carries it off with it. The two outlet pipes join at their distal extremities into a short broader tube and consequently end in one common nozzle, $\mathbf{E}$. The steam pipe, which is uppermost, is short and straight, whilst the lower vapour pipe is broader, longer, and curved. The vapour arising from the drugs in the receptacle is assisted in its exit (1) mainly by the pressure of the current of fresh air entering through the funnel-shaped opening in the cap, $F$, of the tube, so that the drug vapour is kept constantly escaping and is being as rapidly replaced by fresh air ; (2) also to some extent by the suction-like action exerted by the steam as it issues from the boiler tube and passes over the point of exit of the vapour tube ; and (3) to some extent by the pressure of the vapour itself. The steam becomes saturated with the vapour of the drug or drugs used and is distributed through the glass trumpet $\mathrm{G}$, the smaller end of the trumpet being employed for inhalation and the larger end for disinfecting purposes or for impregnating the air of the room. The said trumpet is supported upon a perforated circular platform, which is fixed in position by means of a wire loop surrounding the upper extremity of the tube $H$ and carries four clips and a central raised ring so arranged as to support the trumpet in either position. The exact amount of water required for the boiler is gauged by a small measure which accompanies the apparatus, with which there is also a small spoon for the drug. Fxcept for the glass funnel, the whole apparatus, which is six inches in height, is made in white polished metal. The boiler stands upon a tripod, beneath which is a small metal spirit lamp. These are not shown in the figure.

The advantages claimed for this apparatus may be briefly summed up as follows. 1. It is compact, light, and very simple to operate. 2. The steam and vapour are both driven through a common nozzle instead of through two separate nozzles, thereby making the intermixing absolute and insuring a more concentrated vapour. 3. Disinfectants used in a vaporous condition have a much more beneficial effect than when used in the ordinary way, and the apparatus fully vaporises the drug or drugs employed. 4. The drug or drugs used are quite unmixed with the vapour or the water in the boiler. 5. The consumption of the drug is very economical, 6. The drugs used may be in the sollid, liquid, or crystalline form. 7. The vapour arising from the drug or drugs is so intimately intermixed with the steam that when inhaled it perfectly penetrates every portion of the lung. By the use of this apparatus the vapour, whether inhaled directly from the tube or indirectly through the air of the room, will reach every part of the lung, even the pulmonary alveoli. 8. The apparatus may be set working in a room a quarter of an hour or so previonsly to a patient going to bed, so that the patient will be breathing an atmosphere saturated with the drug; this is most useful and benefrcial in cases of pulmonary tuberculosis, asthma, and chronic bronchitis.

The apparatus will be found useful in the treatment of rhinitĩs, pharyngitis, tonsillitis, laryngitis, asthma, emphysema, phthisis, hay fever, gangrene of the lung, whooping: cough, and other respiratory diseases. The following are examples of substances that can be used for evaporisation or volatilisation in the receptacle: menthol, eucalyptus, carbolic acid, lysol, thymol, mercury, creosote, terebene, stramonium, lobelia, or any combination of these drugs.

Brighton.

$$
\text { A. G. WHITEHORNE-COLE, M.R.C.S., L.R.C.P. }
$$

\section{METAL FINGER GUARD FOR USE AS DIRECTOR.}

SOMETTMES during surgical operations it is very convenient to cut down upon the finger as a guide. When, for instance, in a septic peritonitis following perforated gastric ulcer it is desirable to drain the loins or pelvis the most convenient way of making a counter opening is to cut down from without upon the forefinger inserted in the original wound, because the finger can feel whether anything is in the way or not. If an instrument is inserted for this purpose it may easily involve a piece of intestine in the counter-opening. But if the gloved finger be used unguarded counter puncture has to be made carefully and deliberately lest the glove and, more serious still, the finger of the surgeon beneath it be cut. Again, a large

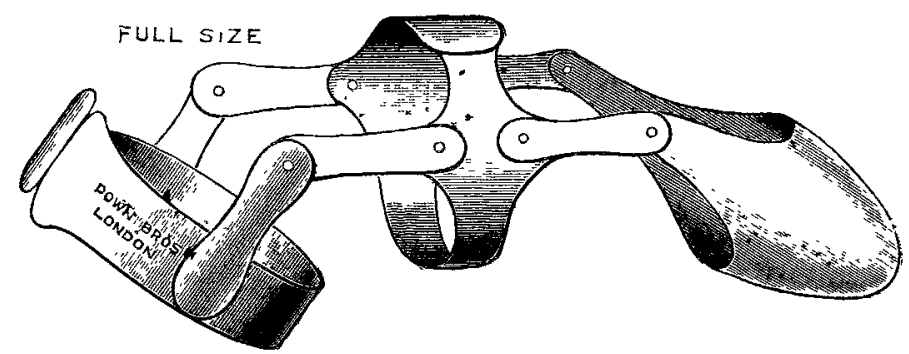

abscess may be pointing and be opened in front of the thigh. It is desired after opening it to make counter punctures for better drainage at the sides. The finger is again the most convenient guide, because it can feel exactly the most dependent point of the abscess cavity. Examples could easily be multiplied and will occur to every surgeon. To protect the finger when thus used as a director I have had the finger guard, as depicted in the accompanying illustration, made for me by Messrs. Down Bros., and have found it very use ful. It allows of as free flexion of the finger as if the latter were unguarded and it can be cut down upon straight away. When used inside the abdomen the forefinger, encased in the finger guard, and the middle finger are inserted together. The latter feels that nothing is in the way, and the guarded forefinger is then cut down upon at once with a single stroke of the knife. The instrument should be made to fit the finger of the surgeon using it.

Charles P. ChILde, B.A., F.R.C.S. Eng., Senior Surgeon, Royal Portsmouth Hospital. 